\title{
Removal of disinfection by-products precursors by polyaluminum chloride coagulation coupled with chlorination
}

\author{
Qinghua Ji ${ }^{\mathrm{a}, \mathrm{b}}$, Huijuan Liu ${ }^{\mathrm{a}}$, Chengzhi Hu${ }^{\mathrm{a}}$, Jiuhui Qu ${ }^{\mathrm{a}, *}$, Dongsheng Wang ${ }^{\mathrm{a}}$, Jing $\mathrm{Li}^{\mathrm{a}, \mathrm{b}}$ \\ a State Key Laboratory of Environmental Aquatic Chemistry, Research Center for Eco-Environmental Sciences, \\ Chinese Academy of Sciences, Beijing 100085, China \\ ${ }^{\mathrm{b}}$ Graduate University, Chinese Academy of Sciences, Beijing 100039, China
}

\section{A R T I C L E I N F O}

\section{Article history:}

Received 21 December 2007

Received in revised form 21 February 2008

Accepted 27 February 2008

\section{Keywords:}

Coagulation

Disinfection by-products formation

potential

Inter-chlorination

Zeta potential

\begin{abstract}
A B S T R A C T
The effect of coagulation coupled with chlorination (i.e., pre-, inter-, and post-chlorination) on the formation of disinfection by-products (DBPs) and the removal efficiency of DBPs precursors were investigated. Compared with coagulation coupling with pre-chlorination, coagulation coupled with inter-chlorination could lead a higher removal efficiency of dissolved organic carbon (DOC), specific ultraviolet absorbance (SUVA) and chloroacetic acids formation potential (CAAsFP). The CAAsFP/DOC value of residual DOC showed that coagulation with inter-chlorination has a beneficial effect on CAAs precursors removal. More DBPs were produced during inter-chlorination than that of pre-chlorination at $\mathrm{pH} 7.5$, while less DBPs were produced during inter-chlorination than that of pre-chlorination at $\mathrm{pH}$ 5.5. In addition, the precipitate of humic acid (HA) after coagulation was chlorinated to study the kinetics of chlorine decay. The results showed that coagulated-HA had a higher reactivity with chlorine than aqueous-HA at $\mathrm{pH} 7.5$. Furthermore, the trends of zeta potential during coagulation process suggested that the distribution of chlorine species had significant influence on the removing of DBPs precursors by coagulation coupled with chlorination.
\end{abstract}

(c) 2008 Elsevier B.V. All rights reserved.

\section{Introduction}

Natural organic matters (NOM) react with chlorine during disinfection to produce a number of halogenated disinfection byproducts (DBPs) in drinking water treatment [1]. Water supplies require removal of such DBP precursors. Enhanced coagulation is suggested by the United States Environmental Protection Agency (USEPA) as an effective method to remove DBPs precursors during water treatment process [2,3].

Water treatment plants frequently use pre-treatment oxidations, such as chlorine, ozone, and chlorine dioxide as the oxidants to control the amount of nuisance aquatic growths [4]. Additionally, these oxidants have been shown to behave as coagulant aids in some waters. However, some studies have suggested that oxidation prior to coagulation tends to hinder dissolved organic carbon (DOC) removal [5,6]. Bose and Reckhow [7] reported that ozone applied to raw water reacted preferentially with humic fraction of NOM which was readily removed from water by coagulation. Ozonation of humic fraction resulted in a decline removal of DOC through coagulation. However, hydrophilic neutral fraction was

\footnotetext{
* Corresponding author. Tel.: +86 10 62849151; fax: +86 1062923558 .

E-mail address: jhqu@rcees.ac.cn (J. Qu).
}

hardly removed by coagulation. Prior ozonation of such organics resulted in an increase removal of DOC through coagulation. Accordingly, a strategy for staged coagulation with intermediate ozonation (coagulation-oxidation-coagulation) was proposed for water treatment to use the beneficial effects of ozone on NOM removal. Singer et al. [8] reported that coagulation coupled with intermediate ozonation was more effective on removing specific ultraviolet absorbance (SUVA) and decreasing DBPs formation than that of coagulation alone.

Coagulant could interact with NOM to change the oxidation reactivity of NOM. There were many researches involved in studying the impact of prior oxidation on coagulation and comparing the NOM removal by coagulation with and without prior oxidation. Staged coagulation with intermediate oxidation (coagulation-ozonation-coagulation) [7] was also studied. And the removal efficiency of DOC and SUVA is substantially enhanced. But this method is not practical for the treatment plant to replace the conventional coagulation at the present time. Dosage of the oxidants during coagulation (inter-oxidation) might be an effective method for the improvement of conventional coagulation to increase DBP precursors removal in practical. However, coagulation coupled with inter-oxidation was rarely studied.

In this paper, we employed sodium hypochlorite as oxidant, humic acid (HA) as NOM to study the effect of inter-oxidation on the 
DBPs precursors removal in coagulation process. The major objectives were to identify and study (1) the effect of chlorination on the humic acid structure; (2) the reaction mechanism of sodium hypochlorite $(\mathrm{NaOCl})$ with humic acid in the presence of polyaluminum chloride (PACl), and (3) the removal efficiency of DBPs precursors by $\mathrm{PACl}$ coagulation coupled with inter-chlorination. The results of this study might provide new method of enhanced coagulation and useful information involved in these processes.

\section{Materials and methods}

\subsection{Experimental materials}

(1) Natural organic materials. Isolated humic acid from soil was used as source of NOM. Soil collected from a wetland at the edge of a lake in North China has a high content of organic material.

(2) Polyaluminum chloride. The electrolysis process was employed to prepare $\mathrm{PACl}$ [9], which contains significant quantities of the active species $\mathrm{Al}_{13}$ polymer [10]. Speciation of the $\mathrm{PACl}$ was determined by Ferron method [11]. The total aluminum concentration $\left(\mathrm{Al}_{\mathrm{T}}\right)$ of $\mathrm{PACl}$ was $13.57 \mathrm{~g} / \mathrm{L}$. The chemical species of hydrolyzed $\mathrm{Al}(\mathrm{III})$ were divided into three types: $\mathrm{Al}_{\mathrm{a}} 2.7 \%$, $\mathrm{Al}_{\mathrm{b}}$ 89.9\% and $\mathrm{Al}_{\mathrm{c}} 7.4 \%$, with $\mathrm{OH} / \mathrm{Al}$ molar ratio (simplified as $\mathrm{B}$ values) of 2.36 .

(3) Kaolinite particles were calcined in a muffle furnace at $500^{\circ} \mathrm{C}$ for $4 \mathrm{~h}$ to remove organic impurities, then size fractionated by sedimentation at $\mathrm{pH} 7.5$ to produce monodisperse suspension.

\subsection{Experiment procedures}

Isolated humic acid was dissolved in $0.1 \mathrm{M} \mathrm{NaOH}$ and filtered through a $0.45 \mu \mathrm{m}$ filter, then diluted to Milli-Q water with a sodium bicarbonate of $2 \mathrm{mM}$, potassium nitrate of $3.5 \mathrm{mM}$ and kaolinite for an approximate turbidity of 20 NTU. Jar test were carried out in a jar test apparatus (MY3000-6, Meiyu Inc., Qianjiang). $0.1 \mathrm{M} \mathrm{HCl}$ and $0.1 \mathrm{M} \mathrm{NaOH}$ were used to adjust the $\mathrm{pH}$ to required value. The contents of the jars were rapid mixed at paddle speed of $300 \mathrm{rpm}$ for $2.5 \mathrm{~min}$, followed by slow mixing at $30 \mathrm{rpm}$ for $20 \mathrm{~min}$, and settling for $2 \mathrm{~h}$. The supernatant was collected for measurement of DOC, $\mathrm{pH}, \mathrm{UV}_{254}$.

Three coagulation processes were performed at $\mathrm{pH} 5.5$ and 7.5 in the PACl underdosing and conventional situations, which were as follows: (1) chlorine dosed 30 min before PACl; (2) chlorine dosed simultaneously with $\mathrm{PACl}$ and (3) chlorine dosed $2.5 \mathrm{~min}$ after $\mathrm{PACl}$. DBPs yields were determined after coagulation to calculate the DBPs produced in coagulation processes.

Water samples after coagulation were chlorinated with sodium hypochlorite $(\mathrm{NaOCl})$ with a $\mathrm{Cl}_{2}$ of $20 \mathrm{mg} / \mathrm{L}$ at $\mathrm{pH} 7,20^{\circ} \mathrm{C}$ for $72 \mathrm{~h}$, buffered by $\mathrm{KH}_{2} \mathrm{PO}_{4} / \mathrm{NaOH}$ in $40 \mathrm{~mL}$ vials to determine the DBPs formation potential (DBPsFP). DBPsFP here is defined as the formation potential of residual DOC (DBPs produced in pre-chlorination or inter-chlorination were not included):

Total DBPs $=$ Pre-DBPs + DBPsFP

In addition, water samples after coagulations were concentrated by vacuum rotary evaporation at $40^{\circ} \mathrm{C}$. The concentrated samples were used for gel permeation chromatography to determine the molecular weight distribution of humic acid both after chlorination and coagulation.

\subsection{Analytical methods}

pH was measured by Orion 720 APLUS Benchtop meter (Thermo Orion Co., USA). Zeta potentials were measured by a Zetasizer 2000
(Malvern, UK). Turbidity was measured by $2100 \mathrm{~N}$ IS Turbidimeter (HACH Co., USA). Quantification of HA was accomplished by measuring UV absorbance of samples at $254 \mathrm{~nm}$ by a U-3010 UV-vis spectrophotometer (Hitachi Co., Japan) equipped with $10 \mathrm{~mm}$ quartz cells and measuring DOC by a multi-N/C 3000 analyzer (Analytik Jena AG, Germany). Chlorine concentration was measured by $\mathrm{N}, \mathrm{N}$-diethyl-phenylenediamine (DPD) photometry methods.

Gel permeation chromatography (GPC) was performed with a HPLC system (L-2000, HITACHI Co., Japan). The column employed for GPC was TSK-GEL (Toshiba, G3000PWXL, $7.8 \mathrm{~mm} \times 30 \mathrm{~cm}$, and particle size $6 \mu \mathrm{m})$. The eluent was phosphate buffer $(2.4 \mathrm{mM}$ $\mathrm{NaH}_{2} \mathrm{PO}_{4}, 1.6 \mathrm{mM} \mathrm{Na}_{2} \mathrm{HPO}_{4}, \mathrm{pH} 6.8,0.01 \mathrm{M} \mathrm{CH} \mathrm{CHONa}_{3}$ with a flow rate of $0.6 \mathrm{~mL} / \mathrm{min}$. The sample volume was $20 \mu \mathrm{L}$. Sodiump-styrene sulfonates (PSS $1.37 \mathrm{kDa}$, PSS $4.6 \mathrm{kDa}$, PSS $6.2 \mathrm{kDa}$, and PSS $15.65 \mathrm{kDa}$ ) were used as molecular mass calibration standards.

Trichloromethane (TCM) was analyzed by liquid/liquid extraction with hexane and gas chromatography/electron capture detector (GC/ECD) (Agilent 6890N Series, USA) according to USEPA Method 551.1 [12]. Chloroacetic acids (CAAs, including di-, and tri-chloroacetic acids) were analyzed by liquid/liquid extraction with methyl tert-butyl ether (MTBE) followed by derivatization with acidic methanol and measured by GC/ECD according to USEPA methods 552.2 [13].

\section{Results and discussion}

\subsection{Effect of chlorination on humic acid structure}

Gel permeation chromatography-UV detection was applied to study the structure change of humic acid after chlorination. The comparison of the humic acid structure before and after chlorination is shown in Fig. 1. For the fractions with different molecular weight (MW), the changes of $\mathrm{UV}_{254}$ after chlorination do not follow the same trends. A reduction of $\mathrm{UV}_{254}$ is observed for the fractions with a retention time of 9.00 and $11.50 \mathrm{~min}$, while there is no reduction for the fractions with a retention time range of 11.50-11.90 min. According to the separation mechanism of GPC, higher MW compounds are eluted earlier. A direct reason for this difference is that part of higher MW humic acid are oxidized and transformed into lower MW compounds. The reduction of UV absorbance of higher MW is due to that larger size humic acid is oxidized into smaller size which elute later from the column or the destruction of chromophores. This implies that chlorination do not only destruct chromophores that absorb UV radiation, but also changes the MW distribution of humic acid. The results present in Fig. 1 are similar to that reported by other researcher [14].

GPC-UV profiles of humic acid after coagulation are also shown in Fig. 1. For the humic acid solution with a DOC level of $3.6 \mathrm{mg} / \mathrm{L}$,

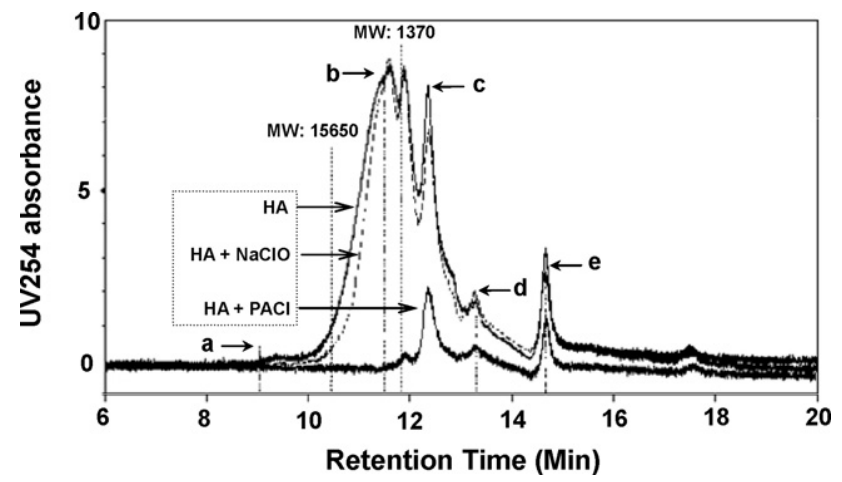

Fig. 1. GPC-UV analysis of humic acid before and after chlorination ( $\mathrm{pH} 7.0 \pm 0.2$, DOC $3.6 \mathrm{mg} / \mathrm{L}$, chlorine $3.0 \mathrm{mg} / \mathrm{L}\left(\mathrm{as} \mathrm{Cl}_{2}\right)$ and $\left.\mathrm{PACl} 0.4 \mathrm{mg} \mathrm{Al} / \mathrm{mg} \mathrm{DOC}\right)$. Note: retention times of peaks a-e are $9.00,11.50,12.36,13.30$ and $14.67 \mathrm{~min}$, respectively. 

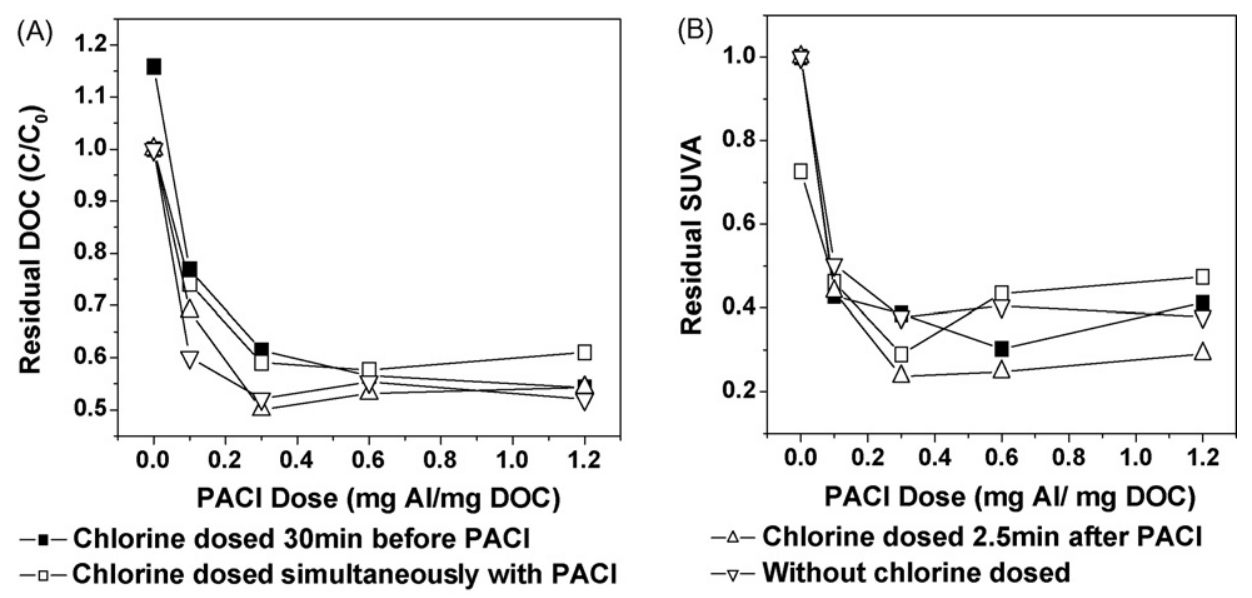

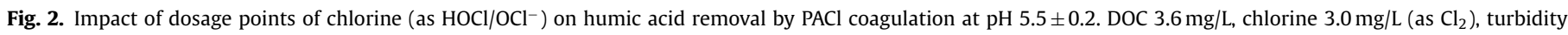
20 NTU. (A) DOC removal and (B) SUVA removal.

Table 1

Quotient $E_{2} / E_{3}$ value of humic acid with different MW

\begin{tabular}{lrrrrr}
\hline & \multicolumn{5}{c}{ Retention time (min) } \\
\cline { 2 - 6 } & 11.50 & 11.90 & 12.36 & 13.30 & 14.67 \\
\hline$E_{2} / E_{3}(\mathrm{HA})$ & 5.17 & 6.00 & 8.78 & 8.24 & 7.38 \\
$E_{2} / E_{3}(\mathrm{HA}+\mathrm{NaClO})$ & 6.00 & 6.58 & 8.22 & 8.55 & 5.88 \\
$\Delta E_{2} / E_{3}$ & +0.83 & +0.58 & -0.56 & +0.31 & -1.50 \\
\hline
\end{tabular}

almost $72 \%$ of DOC can be removed after PACl coagulation. The profiles indicate that coagulation remove the humic acid component selectively. Higher MW humic acid compounds tend to be a higher removal, while lower MW humic acid compounds turn out to be the opposite. After coagulation, the major components of larger size humic acid are removed, while residual humic acid components are relatively with smaller size. These components become the major DBPs precursors during disinfection process.

Another evidence of structure changes of NOM is the evolution of $E_{2} / E_{3}$ (the ratio of $250 / 365 \mathrm{~nm}$ ) value after chlorination. Humic acid with different MW may contain different functional groups. The quotient $E_{2} / E_{3}$ correlates with the molecular size and aromaticity of aquatic humic solutes: when the quotient $E_{2} / E_{3}$ increases, the aromaticity and molecular size of aquatic humic solutes decreases [15]. As shown in Table 1 , it is observed that the quotient $E_{2} / E_{3}$ increases for the compounds with retention time 11.50, 11.90 and $13.30 \mathrm{~min}$ and decreases for the compounds with retention time 12.36 and $14.67 \mathrm{~min}$. The increase of $E_{2} / E_{3}$ is presumably a manifestation of oxidation and halogenation reactions, reflecting changes in the chromophores that can be destructed by chlorine [16]. But this oxidation does not usually lead to complete mineralization of NOM [17]. However, the decrease of $E_{2} / E_{3}$ in the lower MW region was probably attributed to the fragment from larger size molecules which contain low $E_{2} / E_{3}$ value.

These results suggest that the DOC removal by coagulation will be hindered if the chlorination is applied to humic acid before coagulation, because larger sizes humic acid molecules will transform into smaller sizes after chlorination. Bose and Reckhow [7] suggested two-stage coagulation with intermediate oxidation make optimal use of the beneficial effects of oxidation on NOM removal.

\subsection{Removal of DOC and SUVA by PACl coagulation coupled with chlorination}

Coagulations coupled with chlorination for NOM removal were carried out at pH 5.5 and 7.5, and the results are presented in Figs. 2 and 3, respectively. Chlorine dosed 30 min before $\mathrm{PACl}$ (coagulation with pre-chlorination) leads a decrease of DOC removal at
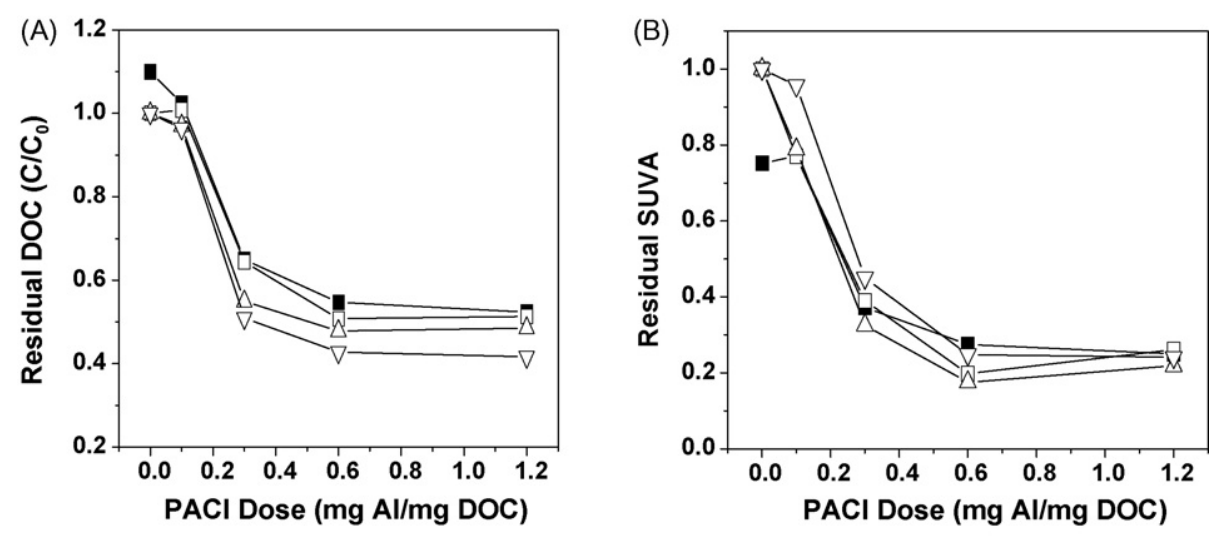

$-\square-$ Chlorine dosed 30 min before PACI
$-\square-$ Chlorine dosed simultaneously with PACI

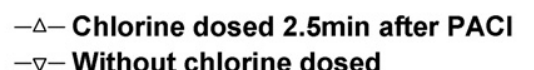

$-\nabla-$ Without chlorine dosed

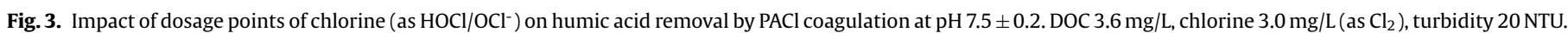
(A) DOC removal and (B) SUVA removal. 
the two pH values. These phenomena are similar to those reported by other researchers $[5,18]$. Organic matters adsorbed on the particle surface can be oxidized into lower molecular size and released into solution (Figs. 2A and 3A). Moreover, the formation of the small organics can inhibit the coagulation and decrease the DOC removal.

The trends of DOC removal vary with different $\mathrm{pH}$ values. A higher DOC and SUVA removal efficiency is observed when chlorine is dosed $2.5 \mathrm{~min}$ after PACl dosing (coagulation with interchlorination) at pH 5.5 (see Fig. 2). However, DOC removal decreases when using coagulation coupled with chlorination (pre- and inter-) at pH 7.5 (Fig. 3A). The SUVA removal efficiency by PACl coagulation without chlorine is less than that of coagulation coupled with interchlorination (Figs. 2B and 3B). SUVA was indicative parameters for the aromaticy in NOM $[8,19]$. So it can be concluded that the aromatic structure of NOM are destructed by chorine, resulting in the reduction of DBPsFP of NOM. According to the report of Morris [20], the proportion of $\mathrm{HOCl}$ and $\mathrm{OCl}^{-}$is affected by the $\mathrm{pH}$ of solution. It can be concluded that during the coagulation process coupled with chlorination, the effect of $\mathrm{pH}$ on the DOC removal efficiency results from the different mechanisms and pathway of chlorination reaction.

\subsection{Reaction between chlorine and humic acid during coagulation process}

To study the effect of chlorine on the humic acid during coagulation progress, coagulated-HA solution and aqueous-HA solution were prepared and were chlorinated. Humic acid was coagulated with $\mathrm{PACl}$ in a dosage of $0.3 \mathrm{mg} \mathrm{Al} / \mathrm{mg}$ DOC (a conventional situation) and settled. And then, the precipitate was transferred to Milli-Q water to obtain a TOC concentration of $4.8 \mathrm{mg} / \mathrm{L}$ (DOC $\leq 0.30 \mathrm{mg} / \mathrm{L}$ ). The DOC contained in precipitate was calculated through residual DOC concentration in the supernatant. Aqueous humic acid was also prepared with a DOC of nearly $4.8 \mathrm{mg} / \mathrm{L}$. $\mathrm{NaHCO}_{3}(2 \mathrm{mM})$ were added to these two different humic acid phases. Chlorine with an initial concentration of $3.0 \mathrm{mg} / \mathrm{L}\left(\right.$ as $\left.\mathrm{Cl}_{2}\right)$ was added to these two solution. Degradations of chlorine in these two humic acid phases are presented in Fig. 4. A higher degradation rate is observed in the coagulated-HA solution in the first $30 \mathrm{~min}$

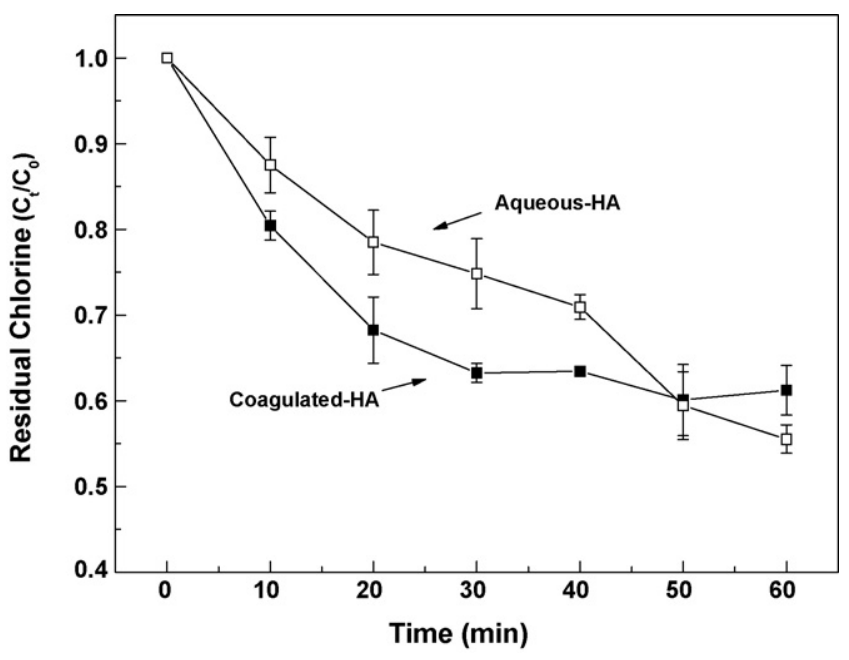

Fig. 4. Degradation of chlorine for aqueous-HA and coagulated-HA (chlorine $3.0 \mathrm{mg} / \mathrm{L}$ (as $\mathrm{Cl}_{2}$ ), $\mathrm{PACl} 0.3 \mathrm{mg} \mathrm{Al} / \mathrm{mg} \mathrm{DOC}, \mathrm{NaHCO}_{3} 2 \mathrm{mM}$, temperature $25^{\circ} \mathrm{C}$ and $\mathrm{pH} 7.5 \pm 0.2)$.

and the residual chlorine become changing slightly after $30 \mathrm{~min}$. However, The concentration of chlorine remaining in aqueous-HA solution after 60 min reaction.

These results indicate that parts of coagulated-HA have higher reactivity, while others might not react with chlorine. Coagulation increases the concentration of HA in a micro-environment and forms a solid-water interface. The negative charge density of the aggregates is lower than aqueous-HA due to the charge neutralization of $\mathrm{PACl}$. Thus, $\mathrm{OCl}^{-}$can be concentrated near the surface of the aggregates and react with $\mathrm{HA}$, resulting in the high reaction rate between chlorine and coagulated-HA. In contrast, negatively charged functional groups of aqueous-HA can hamper $\mathrm{HOCl} / \mathrm{OCl}^{-}$collision because of electrostatic repulsion. Thus, the chlorination reaction will be relatively restrained in aqueousHA solution. Another reason for the high reactivity is probably due to the catalysis of aluminum species. Previous researcher [21] reported that aluminum could catalyze the oxidation process of
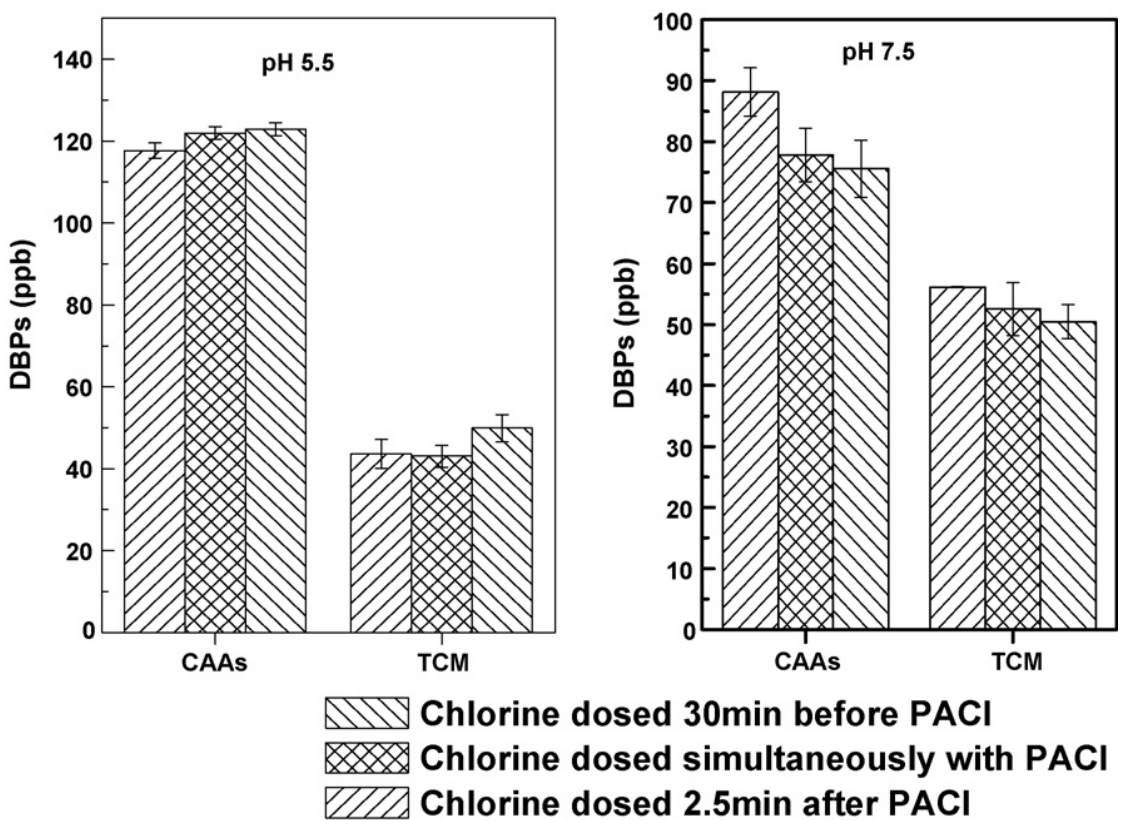

Fig. 5. Yields of DBPs produced during coagulation coupled with chloriantion (DOC $3.6 \mathrm{mg} / \mathrm{L}$, Chlorine $3.0 \mathrm{mg} / \mathrm{L}\left(\mathrm{as} \mathrm{Cl}_{2}\right), \mathrm{NaHCO}_{3} 2 \mathrm{mM}$ and temperature $25^{\circ} \mathrm{C}$ ). 
sodium hypochlorite with polyamide membrane. The aggregates can provide interface for the catalytic reaction.

Since coagulated-HA solution is heterogeneous, humic acid is presented as "solid state". Chlorine can hardly react with compounds entrapped in aggregates. Then, higher reaction rate of chlorination primarily occurred covering the interface of these "solid state" HA. Thus, the negative surface charges density of coagulated-HA increased after reaction with chlorine. With the increasing charge density, higher reaction rate slowed down, and furthermore, negatively charged functional groups on surface benefit its subsequent adsorption and precipitation by $\mathrm{PACl}$, leading a better removal of SUVA.

For the further study, attention is drawn to the production of DBPs during pre- and inter-chlorination processes. CAAs and TCM production were determined and the results are presented in Fig. 5. Both CAAs and TCM productions are higher during the process of chlorine dosed $2.5 \mathrm{~min}$ after $\mathrm{PACl}$ at $\mathrm{pH} 7.5$. This indicates that the presence of $\mathrm{PACl}$ has enhanced the formation of CAAs and TCM at $\mathrm{pH}$ 7.5. As in the present result, $\mathrm{PACl}$ species change the organic charge, which may increase the reactivity of humic acid with chlorine. However, the opposite results are found at $\mathrm{pH}$ 5.5. CAAs and TCM productions are lower when chlorine dosed $2.5 \mathrm{~min}$ after $\mathrm{PACl}$. This study indicates that $\mathrm{pH}$ value shows greatly influence on the reaction between humic acid and chlorine in the presence of $\mathrm{PACl}$.

The $\mathrm{pH}$ adjustment affects the distribution of $\mathrm{HOCl}$ and $\mathrm{OCl}^{-}$. Hypochlorous acid is a weak acid which dissociates in aqueous solution [20].

$\mathrm{HOCl} \rightleftharpoons \mathrm{H}^{+}+\mathrm{OCl}^{-}, \quad K_{\mathrm{HOC1}}=2.9 \times 10^{-8} \quad\left(\mathrm{p} K_{\mathrm{HOCl}}=7.54, \quad 25^{\circ} \mathrm{C}\right)$

At low $\mathrm{pH}$ values, hypochlorous acid $(\mathrm{HOCl})$ is a predominant species. Increasing $\mathrm{pH}$ value will lead a high proportion of hypochlorite $\left(\mathrm{OCl}^{-}\right)$species.

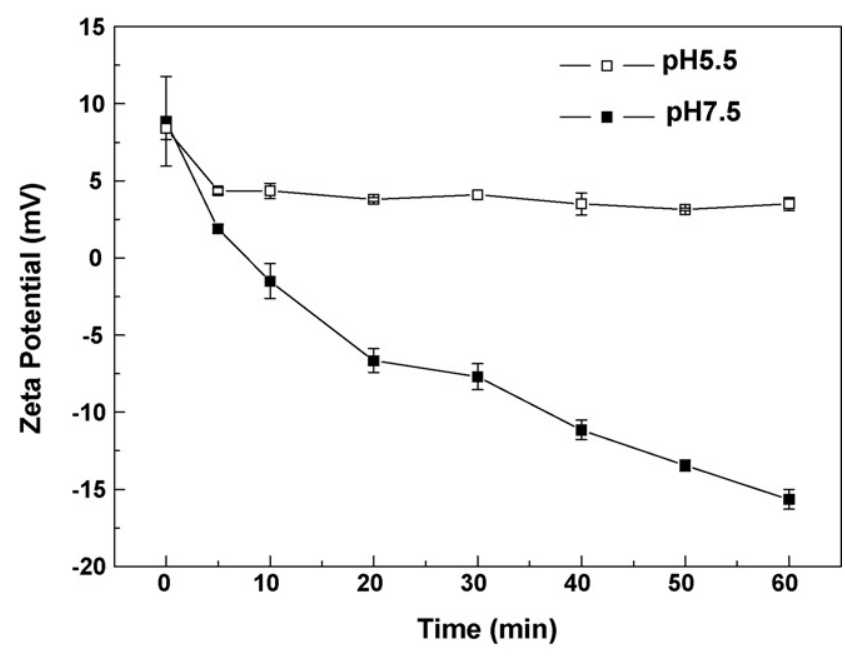

Fig. 6. Influences of $\mathrm{pH}$ on zeta potentials of the particles during coagulation process in the presence of chlorine (chlorine $3.0 \mathrm{mg} / \mathrm{L}$ (as $\mathrm{Cl}_{2}$ ), $\mathrm{NaHCO}_{3} 2 \mathrm{mM}$, temperature $25^{\circ} \mathrm{C}, \mathrm{PACl} 0.4 \mathrm{mg} \mathrm{Al} / \mathrm{mg} \mathrm{DOC}$ at $\mathrm{pH} 7.5$ and $0.2 \mathrm{mg} \mathrm{Al} / \mathrm{mg}$ DOC at $\mathrm{pH} 5.5$ ).

For the purpose of demonstrating the above conclusion, a special experiment was performed in which zeta potentials of particles were measured during coagulation process with inter-chlorination at different $\mathrm{pH}$ condition. Since the reaction activity between HA and chlorine was influenced by zeta potential of $\mathrm{HA}$, different $\mathrm{PACl}$ dosages were chosen at different $\mathrm{pH}(\mathrm{pH} 5.5$ and 7.5) to make the initial zeta potentials nearly the same. The results are presented in Fig. 6. Progressive decrease of zeta potential at pH 7.5 is consistent with the phenomena in Fig. 4, indicating a high reaction rate between chlorine and humic acid. There is, however, only a slight decrease of zeta potential at $\mathrm{pH} 5.5$, implying the low reactivity rate between coagulated-HA and $\mathrm{HOCl}$. These differences result in the
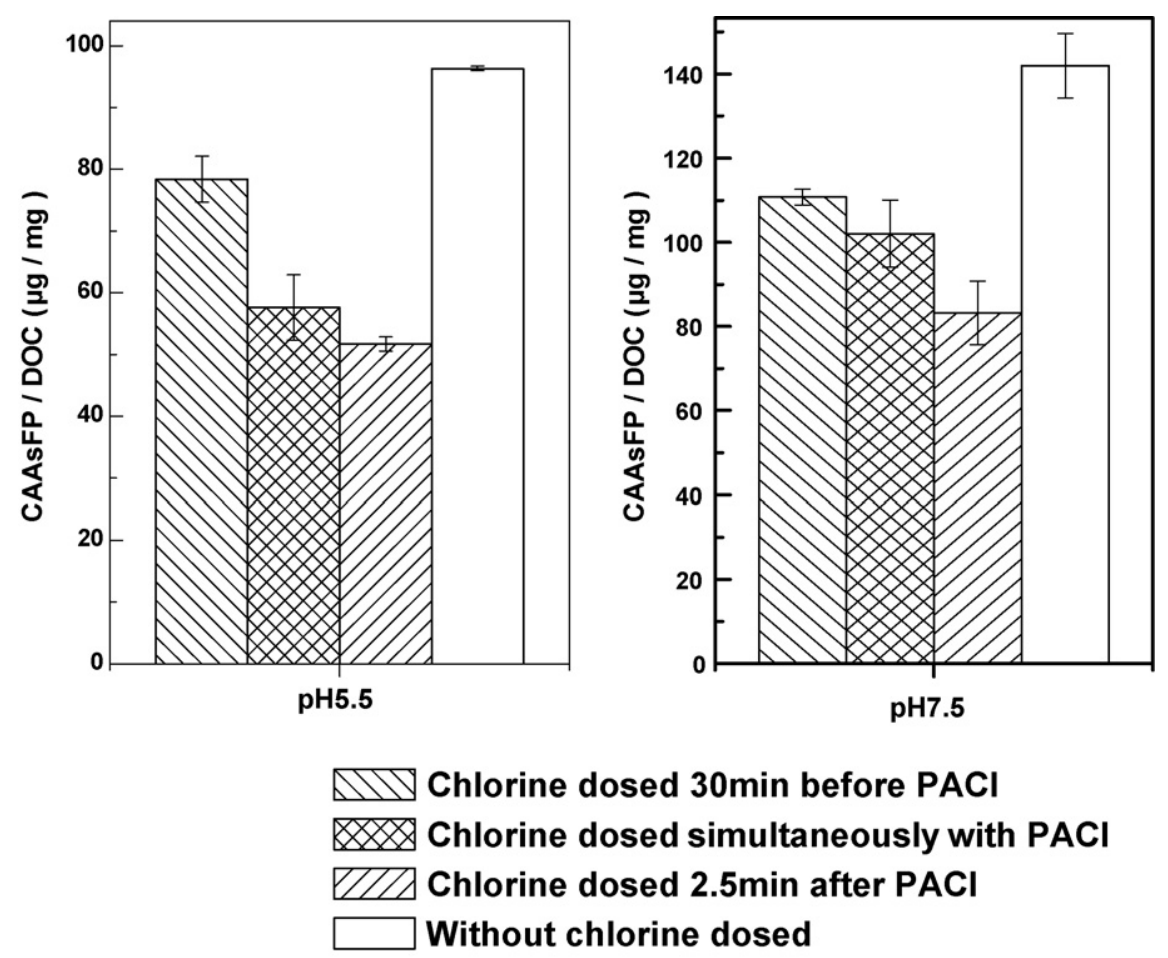

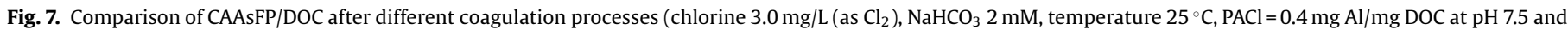
$0.2 \mathrm{mg} \mathrm{Al} / \mathrm{mg} \mathrm{DOC}$ at $\mathrm{pH} 5.5$ ). 
dissimilar formation of DBPs during coagulation process at $\mathrm{pH} 5.5$ and 7.5 (see Fig. 5).

The results of the above experiments indicate that, while coagulation coupled with inter-chlorination, the removal efficiency of DOC is affected by the oxidant species, as well as the NOM chemical structure. On the basis of overall results, it is proposed that the formation of aggregates during coagulation process inhibits the reaction between chlorine and the organics that has been entrapped in the aggregates. At $\mathrm{pH} 7.5$, higher reaction rate of chlorination occurred covering the interface of these aggregates. The duration of coagulation process was about 20-30 min, during which the higher reaction rate occurred (see Fig. 4). As a result, more DBPs were produced during the coagulation process at pH 7.5 (see Fig. 5). While at $\mathrm{pH} 5.5, \mathrm{HOCl}$ is prevalent. Although the formation of aggregates increased the concentration of $\mathrm{HA}$ in micro-environment and the zeta potential, the reactivity of $\mathrm{HOCl}$ with coagulated$\mathrm{HA}$ was less influenced by zeta potential than that of $\mathrm{ClO}^{-}$with coagulated-HA (see Fig. 6). Therefore, the reaction rate of chlorine with coagulated-HA was not increased. Furthermore, HA was entrapped in the aggregates and could not contact with chlorine. Thus, less DBPs were produced during the coagulation process at $\mathrm{pH}$ 5.5 (see Fig. 5). The aggregates can "protect" humic acid with larger size which is readily removal by $\mathrm{PACl}$ coagulation. Organic matter with smaller size which is hardly removal from water appears to change the specific organic charge by reacting with chlorine, causing an increased removal of DOC.

\subsection{Removal of CAAs precursors by PACl coagulation coupled with chlorination}

Coagulations were performed at $\mathrm{PACl}$ optimum dosage $(0.2 \mathrm{mg}$ $\mathrm{Al} / \mathrm{mg} \mathrm{DOC}$ at $\mathrm{pH} 5.5$ and $0.4 \mathrm{mg} \mathrm{Al} / \mathrm{mg} \mathrm{DOC}$ at $\mathrm{pH} 7.5$ ). The CAAs formation potential (CAAsFP) of residual DOC after coagulation are presented in Fig. 7. CAAs concentrations $(\mu \mathrm{g} / \mathrm{L})$ are normalized per unit of DOC $(\mathrm{mg} / \mathrm{L})$. CAAsFP/DOC values follow the rank order: chlorine dosed 30 min before $\mathrm{PACl}>$ chlorine dosed simultaneously with $\mathrm{PACl}>$ chlorine dosed $2.5 \mathrm{~min}$ after $\mathrm{PACl}$. The results indicate that coagulation coupled with inter-chlorination has a beneficial effect on CAAs precursors removal. A hypothesis here is that DBPs precursors transform into intermediate products by reaction with chlorine. The intermediate products can readily be coagulated by $\mathrm{PACl}$ and entrapped in the aggregates. As a result, further chlorination reaction tends to be restrained (see Section 3.3).

\section{Conclusions}

Coagulation with inter-chlorination showed higher removal of DOC, SUVA and CAAs precursors than that of coagulation with prechlorination. Coagulation process increased the concentration of HA in a micro-scale ambience and formed a solid-water interface, resulting in the change of chlorination reactivity.

Higher degradation rate of $\mathrm{HA}$ was observed in $\mathrm{PACl}$ coagulatedHA solution than in aqueous-HA solution. More DBPs were produced in inter-chlorination than in pre-chlorination at $\mathrm{pH} 7.5$, while the opposite result was obtained at $\mathrm{pH}$ 5.5. Since $\mathrm{pH}$ affects the distribution of $\mathrm{HOCl}$ and $\mathrm{OCl}^{-}$. These phenomena indicated that the $\mathrm{HOCl}$ reacted with coagulated-HA at low reactivity, while $\mathrm{OCl}^{-}$could react with coagulated-HA quickly for its different charge properties.
Based on these results, inter-oxidation with $\mathrm{pH}$ control was proposed to apply during coagulation process to make efficiently use of oxidant and reduce DOC and DBPs precursors.

\section{Acknowledgments}

This work was supported by National Natural Science Foundation of China (Grant No. 20777087) and the Funds for Creative Research Groups of China (Grant No. 50621804).

\section{References}

[1] S.W. Krasner, M.J. McGuire, J.G. Jacangelo, N.L. Patania, The occurrence of disinfection by-products in U.S.drinking water, J. Am. Water Works Assoc. 81 (1989) 41-53.

[2] C. Volk, K. Bell, E. Ibrahim, D. Verges, G. Amy, M. Lechevallier, Impact of enhanced and optimized coagulation on removal of organic matter and its biodegradable fraction in drinking water, Water Res. 34 (2000) 3247-3257.

[3] G. Crozes, P. White, M. Marshall, Enhanced coagulation: its effect on NOM removal and chemical costs, J. Am. Water Works Assoc. 87 (1995) 78-89.

[4] P.C. Singer, D.A. Reckhow, Chemical oxidation, in: R.D. Letterman (Ed.), AWWA Water Quality and Treatment: A Handbook of Community Water Supplies, McGraw-Hill Inc., 1999.

[5] D.A. Reckhow, P.C. Singer, Removal of organic halide precursors by preozonation and alum coagulation, J. Am. Water Works Assoc. 76 (1984) 151-157.

[6] M. Edwards, M.M. Benjamin, Effect of preozonation on coagulation-NOM interactions, J. Am. Water Works Assoc. 84 (1992) 63-72.

[7] P. Bose, D.A. Reckhow, The effect of ozonation on natural organic matter removal by alum coagulation, Water Res. 41 (2007) 1516-1524.

[8] P.C. Singer, C. Arlotta, N. Snider-Sajdak, R. Miltner, Effectiveness of preand intermediate ozonation on the enhanced coagulation of disinfection by-product precursors in drinking water, Ozone Sci. Eng. 25 (2003) 453-471.

[9] G.J. Lu, J.H. Qu, H.X. Tang, The electrochemical production of highly effective polyaluminum chloride, Water Res. 33 (1999) 807-813.

[10] H.J. Liu, J.H. Qu, C.Z. Hu, S.J. Zhang, Characteristics of nanosized polyaluminum chloride coagulant prepared by electrolysis process, Colloids Surf. A: Physicochem. Eng. Aspects 216 (2003) 139-147.

[11] D.R. Parker, P.M. Bertsch, Identification and quantification of the "Al13" tridecameric aluminum polycation using ferron, Environ. Sci. Technol. 26 (1992) 908-914.

[12] EPA, Method 551.1-determination of chlorination disinfection byproducts, chlorinated solvents, and halogenated pesticides/herbicides in drinking water by liquid-liquid extraction and gas chromatography with electron-capture detection, Revision 1.0. Environmental Protection Agency, 1995.

[13] EPA, Method 552.2-determination of haloacetic acids and dalapon in drinking water by liquid-liquid microextraction, derivation, and gas chromatography with electron capture detection, Revision 1.0. Environmental Protection Agency, 1995

[14] B. Georg, E.C. Georg, T.G. Egil, K.H. Jan, M. Silvano, High-performance size exclusion chromatography of chlorinated natural humic water and mutagenicity studies using the microscale fluctuation assay, Environ. Sci. Technol. 19 (1985) 422-426.

[15] J. Peuravuori, K. Pihlaja, Molecular size distribution and spectroscopic properties of aquatic humic substances, Anal. Chim. Acta 337 (1997) 133-149.

[16] G.V. Korshin, M.M. Benjamin, H.S. Chang, H. Gallard, Examination of NOM chlorination reactions by conventional and stop-flow differential absorbance spectroscopy, Environ. Sci. Technol. 41 (2007) 2776-2781.

[17] S.D. Chang, P.C. Singer, The impact of ozonation on particle stability and the removal of TOC and THM precursors, J. Am. Water Works Assoc. 83 (1991) 71-79.

[18] A.G. Collins, M.R. Farvardin, Preozonation as an aid in the coagulation of humic substances-optimum preozonation dose, Water Res. 23 (1989) 307-316.

[19] M. Kitis, T. Karanfil, J.E. Kilduff, A. Wigton, The reactivity of natural organic matter to disinfection by-products formation and its relation to specific ultraviolet absorbance, Water Sci. Technol. 43 (2001) 9-16.

[20] J.C. Morris, The acid ionization constant of $\mathrm{HOCl}$ from 5 to $35^{\circ}$, J. Phys. Chem. 70 (1966) 3798-3805.

[21] I.C. Tessaro, J.B.A. da Silva, K. Wada, Investigation of some aspects elated to the degradation of polyamide membranes: aqueous chlorine oxidation catalyzed by aluminum and sodium laurel sulfate oxidation during cleaning, Desalination 181 (2005) 275-282. 